\title{
Corneal Confocal Microscopy Anomalies Associated with Cowden Syndrome: A Case Report
}

\author{
Sandro Sbordone ${ }^{a} \quad$ Alfonso Savastano $^{a} \quad$ Maria Cristina Savastano $^{b}$ \\ Vito Romano $^{a} \quad$ Mario Bifani $^{a} \quad$ Silvio Savastano ${ }^{c}$ \\ ${ }^{a}$ Eye Department, Second University of Naples (S.U.N.), Naples, ${ }^{b}$ Eye Department, \\ Catholic University, Rome, and 'Eye Department, 'Fabrizio Spaziani' Hospital, \\ Frosinone, Italy
}

\section{Key Words}

Corneal alterations · Corneal confocal microscopy · Cowden syndrome · Multiple hamartoma syndrome

\begin{abstract}
Purpose: To describe bilateral corneal alterations through confocal microscopy in a patient affected by Cowden syndrome (CS). Methods: Evaluation of Schirmer's, fluorescein, and lissamine green dye tests. Confocal microscopy was performed in both eyes to investigate corneal abnormalities. Results: Slit lamp observation showed the focal involvement of anterior stromal and epithelial layers. Schirmer's, fluorescein, and lissamine green dye test results were regular, while corneal confocal examination confirmed the disorganization of anterior stromal and epithelial layers in both eyes. Conclusion: CS is a rare autosomaldominant systemic disorder. In our case, confocal analysis revealed predominance of alterations in the anterior stromal corneal layer, showing an increase of reflectivity, and a totally unstructured architecture in the epithelium layer. Even though the main purpose remains the prevention and the early diagnosis of different systemic tumors that could occur in affected patients, corneal confocal evaluation could play an important role in the early diagnosis of this rare disease.

(c) 2013 S. Karger AG, Basel
\end{abstract}

\section{Introduction}

Cowden syndrome (CS) was first described in 1963 by Lloyd and Dennis [1]. CS is among a larger group of diseases also known as multiple hamartoma syndrome [2]. It is a

Sandro Sbordone, MD

Eye Department, Second University of Naples

Via Pansini n. 5

IT-80100 Naples (Italy)

E-Mail sandro.omar@alice.it 
Sbordone et al.: Corneal Confocal Microscopy Anomalies Associated with Cowden Syndrome: A Case Report

rare, autosomal-dominant, multisystemic disorder characterized by diffuse hamartomatous tissue overgrowth and increased risk of breast, thyroid, and endometrial cancers $[3,4]$. Approximately $80 \%$ of cases seem to arise from germline mutations in the PTEN gene (phosphatase and tensin homologue gene, 10q22-23 locus) gene, which is a tumor suppressor gene [5]. Clinically, germline mutations in PTEN have also been associated with Bannayan-Riley-Ruvalcaba syndrome, Proteus or Proteus-like syndrome, adult LhermitteDuclos disease and autism-like disorders [6]. Gicquel et al. [7] reported a possible correlation of CS with retinal angioma and, more recently, Mansoor and Steel [8] described a case report of proliferative retinopathy in CS. We report the case of a young female patient affected by CS, who complained of ocular discomfort and epiphora. She came to our observation for a complete ophthalmological evaluation in order to establish a possible correlation between CS and ocular disease.

\section{Materials and Methods}

Our case report describes a 14-year-old female patient. She complained of severe epiphora and photophobia over the last 2 years. The study adhered to the Declaration of Helsinki, receiving written informed consent from the parents of the minor in order to capture images of the patient's eyes. A complete ophthalmological evaluation was performed, including: best-corrected visual acuity (BCVA) in Early Treatment Diabetic Retinopathy Study (ETDRS) letters, and biomicroscopy of anterior and posterior segments.

Her BCVA was 33 ETDRS letters in each eye. Both eyes were normal except for the anterior segment. Slit lamp examination showed diffuse corneal epithelial alterations with tiny fibrosis of the anterior corneal stroma and whitish epithelial dots (fig. 1a-f). Schirmer's test with topical anesthesia, and fluorescein and lissamine green dye tests were performed. In order to investigate the microscopy details of the cornea, confocal evaluation was carried out with corneal Z-ring (Confoscan 4, Nidek Technologies, Padua, Italy). The patient underwent confocal examination after local anesthesia with 2 drops of oxybuprocaine hydrochloride $0.4 \%$.

\section{Results}

Schirmer's test with topical anesthesia was normal in both eyes, with tear production of more than $15 \mathrm{~mm}$ in $5 \mathrm{~min}$ (fig. 1d) [9]; fluorescein and lissamine green dye tests were negative. Confocal analysis was considered necessary to obtain the objective and microscopically defined image of the cornea. Although the density of keratocyte cells was normal in posterior and intermediate corneal stroma ( 495.2 and 795.6 cells $/ \mathrm{mm}^{2}$, respectively), it was reduced in the anterior stroma (300.2 cells $/ \mathrm{mm}^{2}$ ) (fig. 2). Stromal reflectivity was normal in posterior and intermediate layers, and the stromal nerves looked normal as well. However, stromal reflectivity was higher than normal in the anterior stroma and the nervous subbasal nerve plexus was not appreciable. The thickness of the corneal epithelial layer was approximately $30 \mu \mathrm{m}$, showing a decrease with respect to the normal value of $50 \mu \mathrm{m}$ [10]; also, the regular architecture had disappeared. The Bowman's layer revealed irregular fibrosis (fig. 2). A well-ordered epithelial structure from basal cells to superficial cells was not appreciable and enlarged activated epithelial cells, with highly reflective nuclei, were observable, as occurs in inflammatory chronic disease [11] (fig. 2). 
Sbordone et al.: Corneal Confocal Microscopy Anomalies Associated with Cowden Syndrome: A Case Report

\section{Discussion}

CS is a rare disorder characterized by diffuse and small hamartomas, commonly identified on the skin and in mucous membranes (i.e. mouth and nose), even though it can also affect the intestinal region as well as other areas. Moreover, patients with CS have an increased risk of developing cancer involving the breast, thyroid, and uterus. The difficulty in diagnosing CS does not allow an exact estimate of its prevalence $(1: 200,000-250,000$ persons) and incidence $(1: 1,000,000)$ [12]. Nowadays, prevention and early diagnosis of the development of tumors in these patients play an important role. In our report, we described corneal alterations in a young patient affected by CS. Despite the fact that the patient complained of photophobia and showed epithelial corneal alterations similar to the ones caused by a long-lasting eye drop therapy or by the chronic abuse of contact lenses, alterations to the lissamine, fluorescein and Schirmer's tests were not appreciable. Confocal analysis revealed predominance of alterations in the anterior stromal corneal layers, showing an increase of reflectivity, and a totally unstructured architecture in the epithelium layer. Multicentric investigations on a greater number of patients would be necessary to evaluate the possible correlation between CS and corneal changes. The diagnosis of CS exposes the patient to an increased risk of breast cancer $(25-50 \%$ compared to $12 \%$ in the normal population), thyroid cancer (3-10\% compared to $1 \%$ in the normal population) and uterine cancer (5-10\% compared to $2.5 \%$ in the normal population) [6]. Once diagnosed, the patient will undergo testing for the prevention of such tumors to ensure early diagnosis. We would like to highlight this particular corneal alteration because it could be useful for early diagnosis of CS if a correlation between these 2 conditions is found in the future. Moreover, when CS is suspected, genetic investigation could reveal important information concerning this possible correlation.

\section{Disclosure Statement} tioned.

The authors have no proprietary or financial interest in any material or device men-

\section{References}

1 Lloyd KM 2nd, Dennis M: Cowden's disease. A possible new symptom complex with multiple system involvement. Ann Intern Med 1963;58:136-142.

-2 Amer M, Mostafa FF, Attwa EM, Ibrahim S: Cowden's syndrome: a clinical, immunological and histopathological study. Int J Dermatol 2011;50:516-521.

-3 Trufant JW, Greene L, Cook DL, et al: Colonic ganglioneuromatous polyposis and metastatic adenocarcinoma in the setting of Cowden syndrome: a case report and literature review. Hum Pathol 2012;43:601-604.

-4 Ngeow J, Mester J, Rybicki LA, et al: Incidence and clinical characteristics of thyroid cancer in prospective series of individuals with Cowden and Cowden-like syndrome characterized by germline PTEN, SDH, or KLLN alterations. J Clin Endocrinol Metab 2011;96:2063-2071.

$\checkmark 5$ Conti S, Condò M, Posar A, et al: Phosphatase and tensin homolog (PTEN) gene mutations and autism: literature review and a case report of a patient with Cowden syndrome, autistic disorder and epilepsy. J Child Neurol 2011;27:392-397.

6 Pilarski R: Cowden syndrome: a critical review of the clinical literature. J Genet Couns 2009;18:13-27.

7 Gicquel JJ, Vabres P, Bonneau D, et al: Retinal angioma in a patient with Cowden disease. Am J Ophthalmol 2003;135:400-402.

$>8$ Mansoor Q, Steel DH: Proliferative retinopathy in Cowden syndrome. BMJ Case Rep 2012;2012:bcr1120115273.

-9 Lamberts DW, Foster CS, Perry HD: Schirmer test after topical anesthesia and the tear meniscus height in normal eyes. Arch Ophthalmol 1979;97:1082-1085. 


\begin{tabular}{l|l}
\hline Case Rep Ophthalmol 2013;4:76-80 \\
\hline DOI: 10.1159/000350316 & $\begin{array}{l}\text { @ } 2013 \text { S. Karger AG, Basel } \\
\text { www.karger.com/cop }\end{array}$ \\
\hline
\end{tabular}

Sbordone et al.: Corneal Confocal Microscopy Anomalies Associated with Cowden Syndrome: A Case Report

10 Ehlers N, Heegaard S, Hjortdal J, et al: Morphological evaluation of normal human corneal epithelium. Acta Ophthalmol 2010;88:858-861.

11 Guthoff RF, Baudouin C, Stave J: Atlas of Confocal Laser Scanning in-vivo Microscopy in Ophthalmology Principles and Applications in Diagnostic and Therapeutic Ophthalmology, ed 1. Berlin, Heidelberg, Springer, 2006.

12 Nelen MR, Kremer H, Konings IB, et al: Novel PTEN mutations in patients with Cowden disease: absence of clear genotype-phenotype correlations. Eur J Hum Genet 1999;7:267-273.
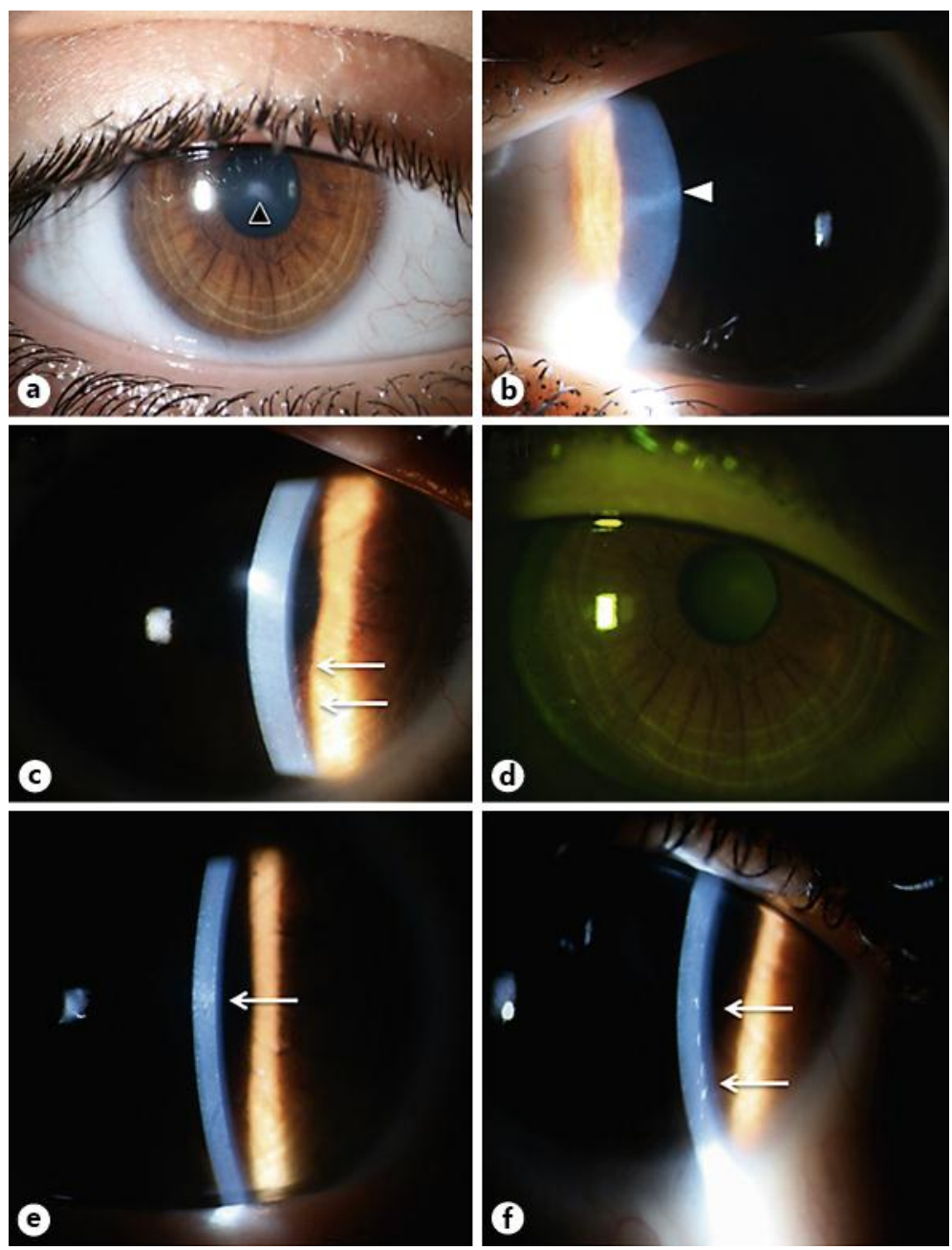

Fig. 1. a Frontal eye image showing white conjunctiva with no signs of irritation and central corneal opacity (black arrowhead). b Slit lamp peripheral cornea observation with tiny subepithelium fibrosis (white arrowhead). c, e, f Slit lamp observations of the central, paracentral and peripheral corneal regions, respectively, show focal white dots corresponding to the alterations (white arrows) in the basal epithelium and in the anterior stromal layer. $\mathbf{d}$ Fluorescein dye test revealed no corneal or conjunctival defects. 


\section{Case Reports in \\ Ophthalmology}

\begin{tabular}{l|l}
\hline Case Rep Ophthalmol 2013;4:76-80 \\
\hline DOI: 10.1159/000350316 & $\begin{array}{l}\text { @ } 2013 \text { S. Karger AG, Basel } \\
\text { www.karger.com/cop }\end{array}$ \\
\hline
\end{tabular}

Sbordone et al.: Corneal Confocal Microscopy Anomalies Associated with Cowden Syndrome: A Case Report
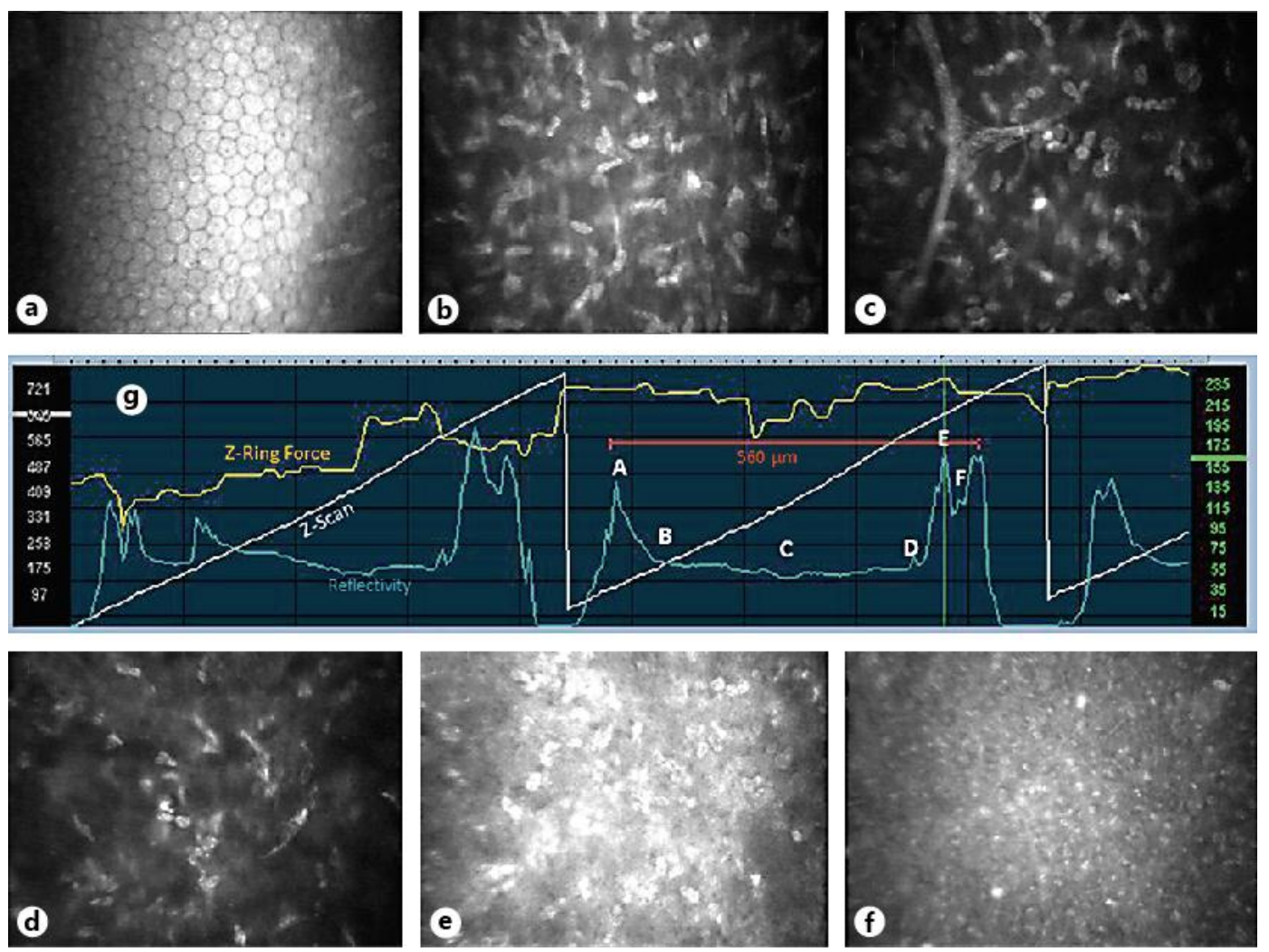

Fig. 2. a Endothelium cells showing regular density $\left(2,665\right.$ cells $\left./ \mathrm{mm}^{2}\right)$ and normal, pleomorphism $(71.6 \%)$ and polymegathism (20.1\%). b Posterior corneal stroma with normal keratocyte density and structure (495.2 cells $/ \mathrm{mm}^{2}$ ). c Intermediate corneal stroma showing normal cell density (795.6 cells $/ \mathrm{mm}^{2}$ ) and reflectivity. Stromal nerve fiber looks normal. $\mathbf{d}$ An increase of reflectivity associated with keratocyte density reduction was observed from the anterior stroma to the pre-Bowman's layer $(300.2$ cells $/ \mathrm{mm}^{2}$ ). e The Bowman's layer revealed irregular fibrosis. f Basal epithelium showing cytoplasm enlargements and hyperreflective nuclei, as occurs in inflammatory chronic diseases. $\mathbf{g} \mathrm{Z}$ scan image shows reflectivity of corneal tissue (azure line), $\mathrm{Z}$ scan (white line) and Z ring force (green line). The letters A-F along the reflectivity line correspond to the reported images in the figure (a-f). 